\title{
EL CONFLICTO SOCIAL Y EL COVID-19 EN LATINOAMÉRICA Y EL CARIBE: EL SECTOR TURÍSTICO COMO DAÑO COLATERAL
}

\author{
SOCIAL CONFLICT AND COVID-19 IN LATIN AMERICA AND THE \\ CARIBBEAN: THE TOURISM SECTOR AS COLLATERAL DAMAGE \\ José Miguel Moreno Carrillo \\ Universidad de Castilla la Mancha \\ jomimorca@gmail.com \\ https://orcid.org/0000-0001-5535-1711 \\ Diego Santos González \\ EAE Business School \\ dsantos@ostelea.com \\ https://orcid.org/0000-0002-2205-8962
}

Recibido/Received: 24/05/2021

Modificado/Modified: 15/10/2021

Aceptado/Accepted: 13/12/2021

\section{RESUMEN}

El contexto político-social, convulso y tenso, que tradicionalmente ha presentado Latinoamérica y el Caribe parece que, en lugar de minimizarse, puede serlo todavía más por culpa de los impactos económicos que está dejando en la región la reciente pandemia sanitaria que azota al mundo.

La COVID 19 golpea con mayor crudeza a los países en desarrollo, que ya se encontraban en una complicada situación en lo político, económico y social, de precariedad y desigualdad, y que, con esta crisis sanitaria mundial no hará más que empeorar. Esta crisis afecta todos los órdenes socioeconómicos y, como no podía ser de otra manera esto también se verá reflejado en el sector turístico, el cual, antes de la pandemia se identificaba por la gran mayoría de los Gobiernos de la región como uno de los ejes tractores para impulsar el desarrollo económico. Una industria que se consideraba clave por su capacidad de repercutir en todos los extractos sociales y fundamentalmente por su capacidad de crecimiento en el medio plazo, pero que lamentablemente se vio golpeada de lleno por las consecuencias colaterales producidas por la pandemia sanitaria y que dieron al traste con la gran mayoría de estrategias turísticas. El objetivo general y principal de este artículo es el describir las diferencias turísticas existentes en esta región, analizar e interpretar los efectos que ha tenido el COVID-19, reflexionar sobre el papel que debe tener la sostenibilidad, especialmente la económica y social, y tratar de interpretar cual puede ser el futuro del turismo, especialmente en los entornos rurales ya que es dónde la incidencia de este desastre se deja sentir más, pues las condiciones de pobreza y vulnerabilidad de las personas se hacen más patentes que en entornos urbanos.

En este sentido, algunos de los datos aflorados en este trabajo muestran duras, pero a su vez esperanzadas, opiniones dentro del sector turístico que destacan la importancia que pueden tener las tendencias vinculadas con nuevos modelos de turismo, como, por ejemplo, el turismo regenerativo.

El desarrollo del trabajo ha sido realizado mediante una metodología de tipo cualitativo, analizando informes, investigaciones y documentos elaborados por las principales instituciones internacionales presentes en la región. Una de las conclusiones que aporta este estudio es que el panorama venidero para las sociedades analizadas lleva consigo tomar más medidas de higiene para la industria turística y de garantizar una seguridad percibida para el visitante mayor que en otras regiones del mundo. También se 
ponen de manifiesto en el presente trabajo dos necesidades urgentes de la industria turística de la región para tratar de ser competitivos. Una es la digitalización y modernización tecnológica del sector turístico en las zonas rurales, y la otra un mayor apoyo e implicación institucional y gubernamental que sirvan de eje vertebrador a empresarios, emprendedores y cooperativistas.

\title{
PALABRAS CLAVE
}

Conflicto; pandemia; turismo; incertidumbre; miedo; globalización

\section{SUMARIO}

1. Introducción. 2. El desarrollo del medio rural un antes y un después. 3. Desigualdad y precariedad. Pobreza y vulnerabilidad. 4. El tránsito de personas. La etapa COVID-19. 5. Migración y turismo. 6. Conclusiones. 7. Bibliografía.

\begin{abstract}
The convulsive and tense political-social context that Latin America and the Caribbean have traditionally presented seems that, instead of being minimized, it may be even more so because of the economic impacts that the recent health pandemic that is hitting the world is leaving in the region .

COVID 19 hits developing countries the hardest, which were already in a complicated political, economic and social situation, of precariousness and inequality, and which, with this global health crisis, will only get worse. This crisis affects all socioeconomic orders and, how could it be otherwise, this will also be reflected in the tourism sector, which, before the pandemic, was identified by the vast majority of the governments of the region as one of the axes tractors to drive economic development. An industry that was considered key due to its ability to have an impact on all social sectors and mainly due to its growth capacity in the medium term, but which unfortunately was hit squarely by the collateral consequences produced by the health pandemic and that ruined with the vast majority of tourist strategies.

The general and main objective of this article is to describe the existing tourist differences in this region, analyze and interpret the effects that COVID-19 has had, reflect on the role that sustainability should have, especially economic and social, and treat to interpret what the future of tourism may be, especially in rural environments, since it is where the incidence of this disaster is most felt, since the conditions of poverty and vulnerability of people are more evident than in urban environments.

In this sense, some of the data emerged in this work show harsh, but at the same time hopeful, opinions within the tourism sector that highlight the importance that trends related to new tourism models may have, such as, for example, regenerative tourism. .

The development of the work has been carried out through a qualitative methodology, analyzing reports, research and documents prepared by the main international institutions present in the region. One of the conclusions that this study contributes is that the future outlook for the analyzed societies entails taking more hygiene measures for the tourism industry and guaranteeing a perceived security for the visitor greater than in other regions of the world. Two urgent needs of the region's tourism industry to try to be competitive are also revealed in the present work. One is the digitalization and technological modernization of the tourism sector in rural areas, and the other is greater support and institutional and governmental involvement that serve as the backbone for businessmen, entrepreneurs and cooperative members.
\end{abstract}

\section{KEYWORDS}

Conflict; pandemic; tourism; uncertainty; fear; globalization.

\section{CONTENTS}

1. Introduction. 2. The development of the rural environment a before and after. 3. Inequality and precariousness. Poverty and vulnerability. 4. The transit of persons. The COVID-19 stage. 5. Migration and tourism. 6. Conclusions. 7. References. 


\section{INTRODUCCIÓN}

Tal y como atestiguan los informes de todas las instituciones turísticas, las restricciones de movilidad y los confinamientos acaecidos por la gestión de la pandemia mundial que está azotando al mundo desde 2020 ha llevado al sector turístico ha encontrarse inmerso en una crisis global.

Como se podía preveer, la mayoría de los países de Latinoamérica y el Caribe en particular, ya con unas economías frágiles y débiles, con desequilibrios económicos, políticos y sociales, anteriores a esta crisis del COVID-19, han sido golpeados con más dureza que aquellos con un sistema económico más sólido. Así lo atestigua el informe del Banco Mundial, sobre América Latina y el Caribe, titulado "La economía en los tiempos del COVID-19", dónde se asegura que algunos de estos países ya afrontaban una crisis antes del brote de la epidemia (2020:6).

Durante años, parecía que el turismo podía ser la industria que catapultase el desarrollo económico en diferentes países de la región. Aunque hemos de ser conscientes que existían grandes diferencias y que la realidad turística en la región era bastante heterogénea. Para Ernest Cañada, toda esta inestabilidad política y violencia vivida, en concreto con mayor crudeza en la década de los ochenta, dio como resultado que la actividad turística en Centroamérica se ralentizara respecto a otras regiones como El Caribe o el sur de México, y que no fuese hasta finales de los noventa cuando esta área comenzase a despegar turísticamente. Razones que explicarían, al menos coyunturalmente, las grandes diferencias existentes todavía hoy entre las estructuras turísticas de estos países (2010:8).

Pese a las diferencias, prácticamente todos los países continuaban apostando, o empezaban a apostar por el turismo como industria económica. Lamentablemente la pandemia ha provocado una crisis social y económica global que afectó de lleno a aquellas economías dependientes del turismo, ya que esta industria se ha visto paralizada casi por completo debido a las restricciones de movilidad decretadas en gran parte del mundo.

Por tratarse de una crisis estructural, no coyuntural, parece que es identificada por los Gobiernos, todavía, como una de las industrias con mayor potencial de crecimiento, por lo que diferentes instituciones de la región estudiada han puesto la esperanza en que el turismo pueda ser, en el corto plazo, un pilar económico fundamental. Para ello necesitarán atraer a turistas tanto a nivel nacional como internacional que, con su gasto, y gracias nuevas tipologías de turismo, como el comunitario, puedan contribuir a mejorar las vidas de los individuos que pueblan las comunicades receptoras.

\section{EL DESARROLLO DEL MEDIO RURAL UN ANTES Y UN DESPUÉS}

La pandemia ha resultado una de las crisis humanitarias internacionales más graves en los últimos cien años, y "esta situación es particularmente crítica para las comunidades rurales, pues son las que más dependen de los recursos naturales ya sea para satisfacer necesidades básicas, para generar ingresos, pero también para asegurar el uso sustentable del territorio" (Prisma, 2020:1).

Lustig y Tommasi, indican que más del $20 \%$ de los residentes urbanos vive en tugurios, donde las condiciones en términos de hacinamiento y vivienda deficiente son extremas, y que cerca de las dos terceras partes de personas pobres vive en zonas urbanas, donde se espera que sufran más crudamente el efecto de la pandemia. No obstante, hay que tener en cuenta que la severidad de la pobreza es mayor en las zonas rurales (2020b:6). 
Para Naciones Unidas es especialmente grave en las zonas rurales y remotas la falta de atención sanitaria y de información en materia de salud afectando en gran medida a los pueblos indígenas (2020:8). Por ello es importante la gestión y valoración de los recursos sanitarios, por la implicación que tienen en la vida de las personas, pues uno de los objetivos intrínsecos de estos es satisfacer las necesidades sociales y económicas junto a la elevación de la calidad de vida. Todo ello lleva a la búsqueda del respeto entre las distintas culturas, al apoyo y convivencia entre ellas, aumentando la valoración de la diversidad sociocultural y biológica en las regiones.

Las diferencias entre las condiciones de vida existentes en el rural y la ciudad en toda Latinoamérica se hacen más patentes cuando, cuando diferenciamos las actividades turísticas que se pueden realizar en ellas. Como ejemplo, el Turismo Rural Comunitario (TRC) que según establecen numerosos informes, una de las dificultades a las que se enfrenta es a la falta de facilidades y acceso a unos servicios públicos de calidad.

Las grandes distancias a los centros urbanizados con mayores recursos y habitantes acentúan los desequilibrios territoriales. De esta forma los proyectos de desarrollo de la población rural pasan por la realización de una verdadera planificación del sector turístico, ya que después del caos vivido por la epidemia actual durante los últimos meses, el Turismo Rural Comunitario (TRC) es una oportunidad para el desarrollo de las regiones interiores, pues no hay que olvidar que "es en las ciudades, donde más gente se concentra y la transmisión del virus ha sido mayor, se espera que los individuos tan pronto puedan salir se desplacen a zonas rurales y menos pobladas" (Araújo y Toubes, 2020:8).

El apoyo y el interés de algunos gobiernos en este sentido se muestra, por ejemplo, según Cardozo, en que el modelo de Turismo Rural Comunitario (TRC) en el Perú ha sido definido desde el Ministerio de Comercio Exterior y Turismo, como "toda actividad turística que se desarrolla en el medio rural, de manera planificada y sostenible, basada en la participación de las poblaciones locales organizadas para beneficio de la comunidad, siendo la cultura rural un componente clave del producto" (2015: 64).

Los proyectos en áreas rurales cara al sector turístico deben perseguir como uno de sus objetivos la sostenibilidad, y desarrollarse de manera que se superen todos los retos a los que tengan que hacerse frente, implicándose todos los actores con su compromiso y esfuerzo personal en el desarrollo rural de la región (Santos et al, 2021:395). Sin embargo, por mucha voluntad que se ponga en llevar a cabo proyectos sostenibles y económicos en muchas de estas regiones es difícil, ya que como atestigua Zibechi, existe desde hace cinco siglos una guerra por la tierra y el territorio, que se ha intensificado por la acumulación por desposesión, como así muestran los estudios y trabajos del Instituto para el Desarrollo Rural de Sudamérica donde se muestra que la mitad del territorio latinoamericano está en disputa entre el capital transnacional y los pueblos (2020: 11).

\section{DESIGUALDAD Y PRECARIEDAD. POBREZA Y VULNERABILIDAD}

El virus no ha provocado sólo una crisis sanitaria, también estamos ante una crisis social e individual, una crisis económica y política, que se carga como una losa pesada a una sociedad donde la solidaridad entre los países se mide en términos de intereses materiales y económicos. Girando, según Del Río, las políticas de los países hacia la unilateralidad y el nacionalismo, amurallándose y protegiéndose tras las fronteras, cuándo las políticas globales y el turismo contribuyeron a expandir el virus (2020:43). 
"Se trata de la experiencia de una fractura entre lo que acontece en el tiempo presente, los hechos y significados construidos en el pasado y las expectativas de un horizonte futuro" (Walker, 2020:166). Los estallidos sociales de 2019, en la mayoría de los países latinoamericanos, fueron una clara advertencia de la urgencia y el desafío que tienen las instituciones públicas de proteger y mirar por sus ciudadanos, respetando sus derechos, y no avasallándolos. Por ello, como dicen Malamud y Núñez, el coste político al que tendrán que enfrentarse algunos gobiernos, tras la situación de crisis protagonizada por el coronavirus será elevado (2020:11).

Para Rebón, la primera ola del virus incidió en las capas medias sociales vinculadas al turismo internacional, afectando progresivamente a la población en general y descargando sus efectos más duros sobre la estructura social de los más necesitados, los que menos tienen (2020:94). Por ello es de máxima importancia la garantía de algunos ingresos se asuma como una obligación y responsabilidad de los gobiernos nacionales de estos países, con la ayuda de otros países en mejor situación económica y social.

Según la revista Prisma, en los territorios rurales es donde más se profundizan las condiciones de exclusión y vulnerabilidad de la población, así es el caso de Centroamérica, región donde los cambios económicos, ambientales y políticos hacen que se incrementen (2020:2). Esto añadido a la exclusión social y de marginación a la que son sometidas muchas personas en los núcleos urbanos, crean un campo de delitos y de inseguridad dónde las principales víctimas y de mayor vulnerabilidad social son los pobres.

A la emergencia sanitaria se ha sumado también la alimentaria, dando como resultado mayor desigualdad y vulnerabilidad social. Al aislamiento producido por los confinamientos preventivos y obligatorios, se le ha sumado la paralización de la actividad laboral y la pobreza a la que muchas familias deben enfrentarse. Por eso, según Abolaisman, la pandemia nos deja una invisibilidad de estos cuidados y una desigualdad educativa, con la implicación social y cultural que ello conlleva (2020:170).

La desigualdad se ha duplicado en los sectores más vulnerables de la sociedad con la pandemia del COVID-19, esta "muestra nuevas expresiones y consecuencias de la desprotección y la desigualdad de las condiciones socioeconómicas y laborales de los/as trabajadores/as de la economía popular para afrontar la cuarentena, derivadas -en gran medida- de la situación de informalidad y precariedad laboral en la que éstos/as se encuentran" (Bonelli y Hopp, 2020: 205).

El mundo rural latinoamericano tiene una losa encima de pobreza y desigualdad, intentando minimizar este peso con los movimientos migratorios del campo a la ciudad, presentando, según Cardozo, una baja calidad de la infraestructura, inequidad en la propiedad de la tierra, sobreexplotación o mal uso de los recursos naturales, poca valoración de "lo rural" y poco acceso a oportunidades, todo ello en las zonas rurales (2015:52). Así son las poblaciones rurales las principales amenazadas por la desposesión de la tierra, $\mathrm{y}$ según Ernest Cañada esta concentración de tierras en inversionistas turístico-residenciales desplaza a la población originaria y a las actividades tradicionales agropecuarias y pesqueras, siendo una amenaza para los principales medios de vida de las comunidades locales $(2010: 21)$.

\section{EL TRÁNSITO DE PERSONAS. LA ETAPA COVID-19}

Hemos asistido a una emergencia sanitaria en la que la salud pública y los sistemas sanitarios de todos los países se han puesto en entredicho y muchos de ellos han sucumbido 
ante la magnitud de la tragedia humana que les ha sorprendido sin estar preparados para contener el virus. Las restricciones de movilidad han sido la tónica general en todos los países, en los cuales una vez pasadas las diferentes olas pandémicas se han puesto a reorganizar sus estructuras sociales y turísticas cara a atraer turistas para levantar una economía muy debilitada tras el desastre del COVID-19. Así en "México, la respuesta inmediata se estima que apuntará a captar turistas en el mercado latinoamericano, para buscar la manera de recuperarse doblemente: de la pandemia y del bajo incremento de turistas desde el norte" (Dachary, 2020: 8).

"En el caso de la actividad turística, los estragos resultarán más adversos que en la mayoría de las actividades económicas, la razón principal es que los viajes, sobre todo los de esparcimiento han sido cancelados en el mundo, una gran cantidad de países han cerrado sus fronteras completamente, y otros han restringido los vuelos hasta llevarlos a una actividad mínima" (García-Mondragón, 2020:53). Muchos ciudadanos desde los países donde les sorprendió la pandemia pudieron volver a sus países de origen, pero muchos otros tuvieron que esperar a la apertura de aeropuertos y levantamiento de confinamientos forzosos. Así el retorno a su país fue para algunos un problema añadido.

El tránsito de personas se ha visto reducido por la crisis sanitaria, abriendo paso a una crisis económica que ha repercutido en todos los sectores de la economía, siendo el turístico uno de los más castigados y perjudicados. Según Grande,

"la retracción de turistas y excursionistas, bien por alargamiento de los periodos de movilidad reducida, como consecuencia de la previsible recesión económica o simplemente por miedo al contagio, restará volumen de negocio a un sector con unos números con poca capacidad de maniobra" (2020:11).

Los movimientos de personas se han restringido y han experimentado una reducción a nivel mundial, de incalculable valor para las economías emergentes de Latinoamérica y el Caribe, por lo tanto, la afirmación de Mora tiene especial interés, al decir qué la caída del turismo internacional y, en general, de viajes internacionales, será un cambio que afectará a varios países latinoamericanos (2020:24). A esto se añade el problema de seguridad humana a los que se enfrentan los gobiernos de estos países, en sus diferentes niveles de responsabilidad y control, como es el terrorismo y los refugiados.

Como ejemplo, de las restricciones mencionadas, tenemos por un lado el caso de Chile, donde según Bárbaro y Demarchi, el "gobierno anunció la clausura temporal de todas las fronteras terrestres, marítimas y aéreas para el tránsito de extranjeros, sin perjudicar a personas de nacionalidad chilena y a los residentes permanentes en el país", y por otro lado está la radical posición de Argentina con respecto a sus compatriotas en que "la situación fue diferente, el cierre de fronteras impidió, incluso, el retorno de los ciudadanos argentinos" (2020:48).

El problema de la dependencia turística en algunos lugares de América Latina y el Caribe viene de largo, y ya había generado algunos problemas de estacionalidad que se han acrecentado con las restricciones impuestas a los turistas de determinados mercados emisores de movilidad turística periódica, que por la pandemia han experimentado cierres parciales y confinamientos perimetrales. Los cierres en los aeropuertos por la suspensión de vuelos han provocado también pérdidas millonarias a las compañías aéreas, $\mathrm{y}$ a todo el sector turístico que se mueve alrededor de estas. 
Para evitar situaciones de dependencia de mercados tradicionales, según Ochoa, "hay que trabajar en una estrategia común para atraer turismo chino, actualmente un cuarto del turismo mundial y en pleno crecimiento y cada vez más en la búsqueda de nuevos destinos" (2018:118). En algunos países latinoamericanos el turismo chino se va acrecentando y consolidando año tras año, significando una parte importante de ingresos no solo para los gobiernos que los acogen sino para muchas familias y comunidades enteras, principal fuente de motor turístico y económico de poblaciones deprimidas y alejadas de los centros urbanos.

"De acuerdo con la Federación Mexicana de Asociaciones Turísticas (FEMATUR), el COVID-19 le costará al turismo mexicano una reducción de hasta 100.000 viajeros chinos, por lo menos en el presente año, lo que se traduciría en una disminución de $60 \%$ respecto a los 167.145 que el país captó durante 2019” (Dachary, 2020: 4).

Uno de los problemas que ha creado esta crisis ha sido paralizar la economía del país, el sustento diario de muchas familias, que si no salían a trabajar no comían ese día. Esto ha generado grandes debates en los dirigentes de todos los países, tomando medidas de acierto para unos más que para otros, por lo que la

“aplicación de medidas drásticas conlleva dos grandes dudas a resolver por los presidentes. La primera, durante cuánto tiempo y en que extensión paralizar la economía. Se trata del mismo dilema que han debido resolver, cada uno a su manera, los dirigentes chinos, los europeos y Donald Trump” (Malamud y Nuñez, 2020: 2).

La sociedad se ha visto afectada por un nuevo modo de vida confinada. Una reclusión, para unos, los más ricos y pudientes, en jaulas de oro, y para otros, los más pobres y vulnerables, en sótanos y bajos sin ventilación. Los hogares han sido el recreo y refugio de las personas frente al peligro que se respiraba en las calles y supermercados. Las actividades diarias se habían limitado a la compra de bienes básicos y necesarios para la propia supervivencia, de esta forma nadie pensaba en viajar ni hacer turismo, por lo menos a corto plazo.

\section{MIGRACIÓN Y PANDEMIA}

Las poblaciones rurales experimentaron un aumento del turismo antes de la pandemia, la actividad turística y comercial era un complemento a su economía familiar y social, siendo el freno del éxodo a las poblaciones urbanas, ya de por sí masificadas con "muchos migrantes en estos sectores y en otros de la economía informal, que trabajan a cambio de un jornal, con el que pagan a diario el arrendamiento de sus cuartos y cubren el resto de sus necesidades" (Lustig y Tommasi, 2020a: 22).

Estas poblaciones han luchado por su territorio, tomando la decisión de quedarse y no abandonarlo para construir una nueva forma de vida social y comunitaria, en el que el turismo sea otra de las principales actividades productivas para salir de la pobreza y mantener una economía de subsistencia estable y respetuosa con su entorno natural y el medio ambiente. Por ejemplo, en el caso de Colombia, estas comunidades tienen un elemento común y es que para Cardozo, "partió de comunidades vulnerables, sean ellas campesinos (Boyacá y Cundinamarca), afrocolombianos (Chocó) y/o desplazados por la violencia (Antioquia), quienes se implicaron en la construcción de su territorio y en la toma de decisiones como un proceso democrático" (2015:107). 
No hay que olvidar la existencia de "las migraciones masivas del campo a la ciudad en búsqueda de asegurar la supervivencia propia" (Gantus, 2020: 117), dónde una de las estrategias personales para la supervivencia tanto para proteger sus vidas como mejorar sus condiciones económicas es la migración hacia diferentes zonas rurales. Según el informe de la Comisión Económica para América Latina y el Caribe (CEPAL), la pandemia está dentro de unos parámetros migratorios donde se estima la movilidad de más de 40 millones de personas, con características tales como el aumento de la migración venezolana, un nuevo canal de migración desde Haití hacia América del Sur y las vulnerabilidades existentes por antonomasia en el tránsito entre Centroamérica, México y los Estados Unidos (2020:1). "La magnitud de este fenómeno es tal que se ha vuelto un elemento estructural de los territorios de origen, destino y tránsito de los migrantes" (Prisma, 2020: 2).

Con la migración, las personas intentan generar opciones vitales ya que carecen de ellas en sus lugares de origen. Estas pertenecen según Cardozo "a las poblaciones que viven en zonas rurales y quienes, en la mayoría de los casos, viven en condiciones de vulnerabilidad como son campesinos, indígenas y afrodescendientes" (2015:105).

Las personas más dadas a la discriminación social son los migrantes sin documentación, muchos de ellos se han quedado en el país después de la entrada en este por estudios o turismo. Por lo que "las medidas unilaterales que han tomado Chile, Perú y Ecuador al solicitar visas de turismo o humanitarias han represado la migración en territorio colombiano; por su parte, Brasil tiene una barrera natural que le permite manejar el fenómeno con mayor solvencia” (Rodríguez, 2020: 101).

Esto presenta un gran desafío para muchos países que acogen inmigrantes por diversas razones, ya que tienen que comprometerse a realizar cambios reales en sus políticas de acogimiento de personas sin hogar, generando oportunidades solidarias para el acceso a servicios básicos de manutención y alojamiento, que les permita acceder a una vida digna y un trabajo, para contribuir a la reconstrucción social y económica después de la crisis sanitaria sufrida por el coronavirus.

Los indocumentados son objeto de exclusión social y de discriminación laboral. La precarización en el trabajo para estas personas tiene unas consecuencias demoledoras para su autoestima, cayendo en un pozo de pobreza del que es difícil salir.

“Además de las penurias ya mencionadas, están sujetos a mayor explotación y, en general, no tienen acceso a los beneficios otorgados a los pobres que son ciudadanos o migrantes legales. Dentro de estos grupos, a su vez, los niños y adultos mayores, las mujeres, los discapacitados y ciertas comunidades particulares (como LBGT) enfrentan carencias y agravios en mayor escala e intensidad" (Lustig y Tommasi, 2020a).

No todos los países mantienen la misma solidaridad entre ellos, y aunque es un hecho que el desarrollo turístico en diferentes regiones es una herramienta de inclusión social, generando ingresos económicos a toda la comunidad disminuyendo la pobreza, según Valderrey, "la falta de oportunidades y la baja remuneración laboral empujan a millones de los ciudadanos a la emigración. Los movimientos migratorios han ido cambiando a través del tiempo, pero siguen siendo un rasgo esencial de América Latina" (2020:125).

\section{CONCLUSIONES}


La crisis sanitaria producida por el COVID ha llevado a los Gobiernos a tomar medidas que limitan los desplazamientos de personas. Esto ha provocado el desplome de la actividad turística en muchos destinos, y para conocer las consecuencias reales que esta pandemia provocará en la industria, habrá que esperar hasta que vuelva la tan ansiada normalidad y ver cómo los diferentes destinos se posicionan en un mercado tan competitivo como es el turístico.

Según los informes consultados para elaborar este texto, parece evidente que hay una serie de retos y necesidades asociados al turismo en las regiones analizadas, que deben constituir los pilares de la futura reconstrucción turística, destacando la necesidad de superar problemas económicos y sociales heredados del pasado. También parece evidente que se debe intentar convertir el turismo después de esta crisis, en un elemento de crecimiento que se apoye en la tan citada sostenibilidad. Para lograrlo se antoja necesaria una eventual colaboración de las multinacionales, emprendedores e instituciones regionales turísticas, tratando de garantizar un reparto equitativo de oportunidades para el desarrollo individual y comunitario (Santos y Moreno Carrillo, 2021:95).

Hemos visto también como nuevas formas de turismo que estaban creciendo antes de la pandemia, como el Turismo Rural Comunitario pueden convertirse en el tan necesario trampolín para que muchas familias puedan vincularse con los beneficios asociados al turismo. Para intentar lograrlo se ha identificado como imprescindible el apoyo gubernamental, para que, entre otras cuestiones, ayude a dotar a los diferentes territorios de las infraestructuras básicas necesarias. No podemos olvidar que según los informes consultados, para poder implementar proyectos vinculados con el Turismo Rural Comunitario, las zonas y comunidades que pretendan implementar esta tipología de turismo se tienen que desarrollar tecnológicamente y así poder competir con otras zonas turísticas ya consolidadas y experimentadas turísticamente.

Por último, se ha identificado que la región estudiada presenta grandes problemas sociales asociados a diferentes flujos migratorios tanto legales como ilegales y que, especialmente en el caso de los refugiados, la industria turística puede ofrecer soluciones para la integración de estas en la comunidad receptora.

\section{BIBLIOGRAFÍA}

Aboslaiman, L. (2020). Consecuencias del COVID-19 en la realidad educativa, social y cultural: el uso de las TIC's. Gastón Mutti, (Coord.). (2020). El tiempo que vivimos. COVID 19 y su impacto en nuestras sociedades. (Editorial de la Universidad Nacional de Rosario, Ed.), Boletín Mirando al Sur núm. 1. Boletín del Comité de Ciencias Políticas y Sociales de la Asociación de Universidades Grupo Montevideo. 169-173.

Araújo, N. y Toubes, D. (2020). Empresa turística: cómo afrontar la gestión después de una crisis sanitaria. El turismo después de la pandemia global análisis, perspectivas y vías de recuperación, 62-70. [consulta 10/02/2021]. En http://bitly.ws/hjoZ

Banco Mundial (2020). La economía en los tiempos del COVID-19. Informe semestral de la región Amética Latina y el Caribe. Abril, 2020.

Bárbaro, A. y Demarchi, P. (2020). La relación Argentina - Chile en el marco de la pandemia del COVID-19. Cooperación en pausa. En Gastón Mutti, (Coord.). (2020). El tiempo que vivimos. COVID 19 y su impacto en nuestras sociedades. (Editorial de la Universidad Nacional de Rosario, Ed.), Boletín Mirando al Sur núm. 1. Boletín del Comité de Ciencias Políticas y Sociales de la Asociación de Universidades Grupo Montevideo. (pp. 46-52). 
Bonelli, J. M. y Hopp, M. V. (2020). La pandemia COVID-19 y después. Reflexiones sobre las consecuencias socioeconómicas y laborales en la economía popular. En Gastón Mutti, (Coord.). (2020). El tiempo que vivimos. COVID 19 y su impacto en nuestras sociedades. (Editorial de la Universidad Nacional de Rosario, Ed.), Boletín Mirando al Sur núm. 1. Boletín del Comité de Ciencias Politicas y Sociales de la Asociación de Universidades Grupo Montevideo. (pp. 204211).

Brea, J. A. F. y Falcó, E. T. (2020). Nuevas oportunidades para el turismo de salud y bienestar. En Martorell, F. J. B. y Arcos, F. J. M. (Directores). (2020). El turismo después de la pandemia global. Análisis, perspectivas y vías de recuperación. Asociación Española de Expertos Científicos en Turismo, 2020, 270. [consulta 15/01/2021]. En http://bitly.ws/hjoZ (pp. 1-12).

Cardozo, N. C. H. (2015). Turismo Rural Comunitario: Una Propuesta Metodológica de Innovación Social para Comunidades en conflicto. Caso Montes de María. Tesis Doctoral en Turismo, Derecho y Empresa. [consulta 09/04/2021]. En http://bitly.ws/hjo2

CEPAL (2020). Los efectos del COVID-19: una oportunidad para reafirmar la centralidad de los derechos humanos de las personas migrantes en el desarrollo sostenible. Informes COVID-19. Noviembre, 2020.

Dachary, A. A. C. (2020). Sociedad, turismo y pandemia: cambio o continuidad. En Martorell, F. J. B. y Arcos, F. J. M. (Directores). (2020). El turismo después de la pandemia global. Análisis, perspectivas y vías de recuperación. Asociación Española de Expertos Científicos en Turismo, 2020, 270. [consulta 10/02/2021]. En http://bitly.ws/hjos (pp. 1-10).

Del Río, L. (2020). Pandemia, Estados, potencias y gobernanza global. En Gastón Mutti, (Coord.). (2020). El tiempo que vivimos. COVID 19 y su impacto en nuestras sociedades. (Editorial de la Universidad Nacional de Rosario, Ed.), Boletín Mirando al Sur núm. 1. Boletín del Comité de Ciencias Políticas y Sociales de la Asociación de Universidades Grupo Montevideo. (p. 3945).

Cañada, Ernest (2010). Turismo en Centroamérica, nuevo escenario de conflicto social. Informe del proyecto, coejecutado por Fundación PRISMA y Alba Sud (mayo 2009 - abril 2011). Editorial Enlace, Managua.

Folmer, O. D. y Luján, A. M. (2005). Estudio de Prospectiva del Sector Turismo en La Pampa. Argentina. Huellas, 24(1), 113-131. https://doi.org/10.19137/huellas-2020-2407

Gantus, D. J. (2020). El Elogio de los Grises. En Gastón Mutti, (Coord.). (2020). El tiempo que vivimos. COVID 19 y su impacto en nuestras sociedades. (Editorial de la Universidad Nacional de Rosario, Ed.), Boletín Mirando al Sur núm. 1. Boletín del Comité de Ciencias Políticas y Sociales de la Asociación de Universidades Grupo Montevideo. (pp. 115-120).

García-Mondragón, L. (2020). La pandemia de COVID-19, una visión desde el empleo en Actividades Turísticas. En Octavio, J. y otros. (2020). La pandemia de COVID-19, una visión desde las ciencias sociales y humanidades. Ecorfan, 79. http://bitly.ws/hjoL (pp. 52-57).

Grande, J. (2020). Turismo rural. Nuevos retos ante la pandemia del coronavirus. En Martorell, F. J. B. y Arcos, F. J. M. (Directores). (2020). El turismo después de la pandemia global. Análisis, perspectivas y vías de recuperación. Asociación Española de Expertos Científicos en Turismo, 2020, 270. [consulta 05/03/2021]. En http://bitly.ws/hjos (pp. 1-13).

Guzowski, C., Recalde, M. y Maidana, F. (2020). Consecuencias de la Pandemia sobre la pobreza energética en América Latina y el Caribe: ¿Un cambio de época o una época de cambio? En Gastón Mutti, (Coord.). (2020). El tiempo que vivimos. COVID 19 y su impacto en nuestras sociedades. (Editorial de la Universidad Nacional de Rosario, Ed.), Boletín Mirando al Sur núm. 1. Boletín del Comité de Ciencias Políticas y Sociales de la Asociación de Universidades Grupo Montevideo. (pp. 53-59).

Llorente, Jose Antonio (2020). Comunicar en cuarentena. Balance de casi tres meses de confinamiento. En Series Desafíos. "Desafío: COVID-19". IDEAS LLYC. (pp. 10-14).

Lustig, N. y Tommasi, M. (2020a). El COVID-19 y la protección social de los grupos pobres y vulnerables en América Latina. (C. y U. de S. A. CEQ Institute, Ed.). San Andrés.

Lustig, N. y Tommasi, M. (2020b, mayo). COVID-19 y la protección social de las personas pobres y los grupos vulnerables en América Latina: un marco conceptual. PNUD América Latina y el Caribe. Serie de documentos de Política Pública, (8), 1-18. [consulta 04/03/2021]. En http://bitly.ws/hjpi 
Malamud, C. y Nuñez, R. (2020). La crisis del coronavirus en América Latina: un incremento del presidencialismo sin red de seguridad, 1-12. Real Instituto elcano, abril. [consulta 07/05/2021]. En http://bitly.ws/hjpt

Mora, J. H. (2020). ¿Qué futuro se vislumbra después del COVID-19? En Cálix, Á. (Coord.) (2020). Perspectivas de transformación en tiempos de emergencia. En Fundación Friedrich-ebertstiftung. Proyecto Regional Transformación Social-Ecológica (Ed.), Cuadernos de la transformación. (pp. 23-32).

Naciones Unidas. (2020). El impacto del COVID-19 en América Latina y el Caribe. Oficina de Naciones Unidas para la Coordinación de Asuntos Humanitarios -OCHA, 1-29. [consulta 03/03/2021]. http://bitly.ws/hjpX

Ochoa, R. (2018). ¿Cambio de ciclo o post-globalización? El impacto en América Latina. En Serbin, Andrés, (Coord.). (2018). América Latina y el Caribe frente a un Nuevo Orden Mundial: Poder, globalización y respuestas regionales. (A. Serbin, Ed.) (1a). Buenos Aires: Icaria Editorial Coordinadora Regional de Investigaciones Económicas y Sociales.

Prisma. (2020). Covid 19: Respuestas de actores y escenarios para la Gobernanza Territorial. PRISMA (Programa Regional de Investigación sobre Desarrollo y Medio Ambiente). Septiembre.

Rebón, J. (2020). La no linealidad del cambio social. En Siegrist L., Escribal F., Sosa N., (Coords.). (2020). El futuro después del COVID-19. Argentina Unida (Gabriela L). Argentina. [consulta 24/03/2021]. En http://bitly.ws/hjqa (pp. 89-96).

Rodríguez, R. F. (2020). Venezuela: un país en tablas. En Rodríguez Pinzón, E. (Dirección y coordinación). (2020). Informe iberoamérica 2020. América Latina ante la protesta y la pandemia. (F. Alternativas, Ed.). Fundación Alternativas. (pp. 101-114).

Santos, D., \& Moreno Carrillo, J. M. (2021). ¿Es necesario regular la práctica de surf durante el verano?. Barataria. Revista Castellano-Manchega De Ciencias Sociales, (28), 93-111. https://doi.org/10.20932/barataria.v0i28.560

Santos González, D., Vogel, M., Karagiannakidis, D., \& Cavalli, C. (2021). Analysing Fondation Pierre Bergé - Yves Saint Laurent: an opportunity for Marrakech to grow sustainable in fashion tourism. Journal of Tourism and Heritage Research, 4(1), 392-413. Retrieved from http://www.jthr.es/index.php/journal/article/view/237

Valderrey Villar, F. J. (2020). América Latina: ¿el escenario de la confrontación comercial? En Defensa, M. de. (2020). La dualidad económica Estados Unidos-China en el siglo XXI. (M. de D. S. G. Técnica, Ed.), Catálogo general de publicaciones oficiales. Madrid: Cuadernos de Estrategia 204. Instituto de Estudios Estratégicos. (pp. 117-171).

Verger, P. (2021). Turismo regenerativo: más allá de la sostenibilidad. [consulta 29/09/2021]. En http://bitly.ws/hjjb

Walker, V. (2020). Teletrabajo docente y universidad. Reflexiones en tiempos de COVID-19. En Gastón Mutti, (Coord.). (2020). El tiempo que vivimos. COVID 19 y su impacto en nuestras sociedades. (Editorial de la Universidad Nacional de Rosario, Ed.), Boletín Mirando al Sur núm. 1. Boletín del Comité de Ciencias Políticas y Sociales de la Asociación de Universidades Grupo Montevideo. (pp. 160-168).

Zibechi, R. (2020). Ni la pandemia ni el estado de sitio frenaron a los pueblos en movimiento. En Celiberti, L. y otros. (2020). Una "nueva normalidad" en disputa ipodremos construir nuevos paradigmas para la sostenibilidad de la vida? Revista periódica Entre Pueblos, núm. 73, 20 págs. (pp. 10-13). 


\section{Breve currículo}

\section{José Miguel Moreno Carrillo}

Licenciado en Sociología y Diplomado en Estudios Avanzados (DEA) (UPSAM). Licenciado en Ciencias Políticas y de la Admón. (San Pablo CEU); Experto Universitario en Análisis Psicosocial de la Violencia de Género (UIB); Dirección y Gestión de Seguridad Integral (UNED), habilitación Director de Seguridad Privada (D.G. Policía-Ministerio del Interior); Aptitud Pedagógica Militar para Centros y Academias Militares; Aptitud Pedagógica Civil (CAP) especialidad Geografía e Historia (UCM). Técnico Deportivo en Alta Montaña (CSD).

\section{Diego Santos González}

Diego Santos González (Pontevedra, 1984). Docente e investigador en el departamento de Ciencias Sociales y Comunicación de EAE-Ostelea-URJC, escuela universitaria de turismo y hospitalidad. Doctor en Sociología (Universidad Rey Juan Carlos, 2016), ha sido capaz de conjugar sus inquietudes intelectuales, sus pasiones personales y profesionales en una tesis doctoral titulada "El mundo sobre las olas. Perspectiva de desarrollo turístico a través del surfing".

Nacer en una familia de agricultores, artistas y deportistas, marcan su personalidad y sus inquietudes personales, por lo que el surf, los viajes, la escritura y la vida rural, son siempre el eje de sus relatos e investigaciones sociales.

Es miembro del grupo de investigación IDITUR-EAE-Ostelea (Centro de Investigación, Divulgación e Innovación Turística) 